\title{
A comparative study of the dietary habits of people who consume organic and conventional food
}

\begin{abstract}
During the last few years the Greek consumers seem to have a tendency towards organic food because of health, food safety and environmental issues. The objective of this study is to compare the dietary habits of people who consume organic food versus those who consume conventional food and to establish any common characteristics between the first groups of people. A questionnaire was used to collect the data that consisted of three parts. The first part contained demographic and anthropometric information, the second information about the dietary habits of the participants and the last part was a Food Frequency Questionnaire (FFQ). The participants completed the questionnaire on their own, without the need of a private interview. The data was analyzed using Epi-info and SPSS. 133 persons took part in the study, 61 of which work at Saint Paul Hospital in Thessaloniki and 65 are costumers of two organic product stores. The results suggest that more people that prefer organic over conventional food are married and that consumers of organic food have healthier dietary habits, since they consume less energy, saturated fat and cholesterol and more vitamins, dietary fibers and antioxidants.
\end{abstract}

Keywords: organic food, conventional food, dietary habits

\author{
Volume 3 Issue I - 2015
}

\author{
Gkoutzelika loanna \\ Department of Clinical Nutrition, Saint Paul General Hospital of \\ Thessaloniki, Greece
}

\begin{abstract}
Correspondence: Gkoutzelika loanna, Head of the Department of Clinical Nutrition in Saint Paul General Hospital of Thessaloniki, Greece, Email igoutzelika@yahoo.com
\end{abstract}

Received: April 27, 20I5 | Published: August 29, 2015

\section{Introduction}

This study took place in the summer of 2009, during my master's degree in "Public health and food safety", in order to establish whether people that choose organic food have healthier dietary habits than those who consume conventional food.

\section{Methodology}

The questionnaire that was used was anonymous and consisted of three parts. The first part contained 11 questions about personal information such as gender, age, height, weight, annual income, level of education, profession, marital status and number of children. The second part involved the dietary habits of the participants. Fist, they were asked if they consumed organic food, for how long, where they bought the organic products from, why they preferred them and which food products they consumed more often. There were also questions to establish that the participants understand that organic products are not what they grow in their private gardens and that there is a strict European legislation about them. Also, there were questions about their general dietary habits which were then divided in healthy and unhealthy. The third part was a food frequency questionnaire (FFQ), which was selected among other methods of collecting information about a person's dietary habits, such as a 24 hour recall, because in the particular study there was no need for a detailed definition of their food intake. More over the FFQ is easier to be filled out by the participant without the need of an expert dietician; it is cheaper and has an adequate repeatability and validity. ${ }^{1}$ The FFQ that was used was the one from the Nurse's Health Study of Harvard University that first took place in $1976,{ }^{2}$ with a few modifications to fit the Greek diet.

133 people took part in the study, 61 of which were employees of Saint Paul General Hospital of Thessaloniki and the rest were costumers of two organic food stores in different parts of Thessaloniki. The data from the first two parts of the questionnaire were processed by Epi Info, in order to establish a correlation between the consumption of organic food and age, level of education, gender, marital status, number of children, annual income, eating breakfast (healthy habit), the number of meals daily (considering the consumption of less than three daily an unhealthy habit, eating fast food 1-2 a month (healthy), removing visible fat from meat before cooking it (healthy), the type of fat they use (olive oil, corn oil, butter etc), the frequency of alcohol consumption (where two drinks a week is considered healthy) using dietary supplements (unhealthy) and a Body mass index (BMI) larger than 25 (unhealthy). The results were considered statistically important when $\mathrm{p}>0.05$.The FFQ was processed with SPSS, to establish a correlation between the consumption of healthier food (more fruits and vegetables, more complex carbohydrates, less saturated fat) and preference of organic food. The mean of the two groups were compared and the Assymp sig (2-tailed). If the Assymp Sig (2-tailed) was smaller than 0.05 , the results were considered statistically important. If the result was statistically important, but the mean was the same between the two groups, then the mean rank was compared and the bigger the mean the bigger the consumption of the particular food that was examined.

\section{Results}

\section{Descriptive analysis}

$27 \%$ of the participants were $19-29$ years of age, $37 \% 30-40$ years old, $24 \% 41-50$ years old, $9 \% 51-60$ and $3 \%$ over 60 years old. $68.5 \%$ were women and $31.5 \%$ men. As to their level of education $6 \%$ of them did not finish high school, $40.6 \%$ were high school graduates, $41.3 \%$ had a university degree and $12 \%$ a masters degree. $19.5 \%$ of the sample earned $0-5000 €$ a year, $10.9 \% 5001-10000 €, 28.9 \%$ $10001-15000 €$ a year, $25 \% 15001-20000 €, 7 \% 20001-25000 €$ and $7 \%$ over $25001 € .43 .9 \%$ were single and $56.1 \%$ married. $51.1 \%$ had no children, $17.3 \%$ had one child, $22.6 \%$ had two children, $6.8 \%$ had three children and only $2.3 \%$ had more than three children. $39.4 \%$ of the participants were consumers of organic food and $60.6 \%$ preferred conventional food. Among the organic food consumers $84.3 \%$ of 
them bought organic food products for over a year, $7.8 \%$ for a month, $3.9 \%$ for two months and $3.9 \%$ for six months. $32.2 \%$ of them bought organic food because they taste better, $25.4 \%$ thought they are more nutritious, $45.8 \%$ thought they are safer and $13.5 \%$ tried them out of curiosity. 19.2\% bought their food from organic food stores, $46.1 \%$ from super-markets, $48.1 \%$ from organic food producers and $17.3 \%$ got them from other sources including their gardens. The food they preferred were $92 \%$ fruit and vegetables, $637.3 \%$ eggs, $42.3 \%$ olive oil, $38.5 \%$ milk and dairy products, $30.8 \%$ meat, $17.3 \%$ pasta and wine and $13.5 \%$ bread. Only $56.9 \%$ of the people that bought organic food products answered that they had the proper European labeling (Figure 1).

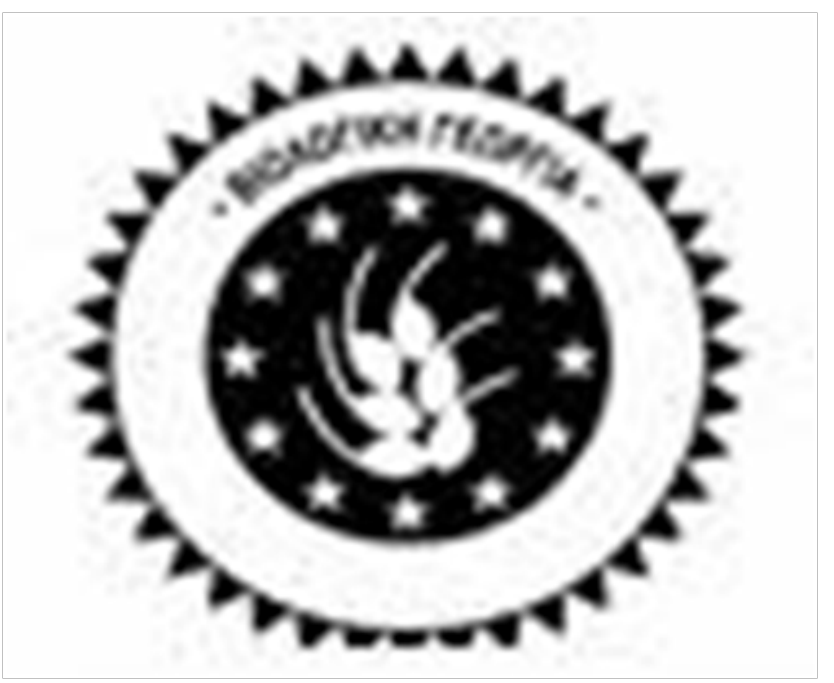

Figure I European label for Greek organic food products.
The rest of the questions concerned all the participants. $35.3 \%$ of the sample acquired their nutritional information from the newspapers, $36.1 \%$ from magazines, $45.9 \%$ from the radio and television, $24.8 \%$ from nutrition books and $17.3 \%$ from nutritionists. $71.5 \%$ eat breakfast. $15 \%$ a ate two meals a day, $29 \%$ three meals a day, $27.6 \%$ four meals a day, $22 \%$ five meals, $5.5 \%$ six meals a day and $0.8 \%$ eight meals a day. $88 \%$ of the participants ate at restaurants or takeout food. $11 \%$ of them did it once a month, $33.9 \%$ once a fortnight, $33.9 \%$ once a week, $15.3 \%$ two to three times a week and $7.6 \%$ more than three times a week. $74.4 \%$ of the sample removed most of the visible fat before cooking their food. $94.7 \%$ of them used olive oil for cooking and the rest corn oil and butter. $79.9 \%$ drunk alcohol. $35.2 \%$ of them drunk one glass a week, $25.7 \%$ two glasses, $25.3 \%$ three glasses $8.6 \%$ eight glasses a week and $2.9 \%$ drunk more than two drinks a day. $12.2 \%$ were on a special diet (pregnancy, diabetes, weight loss etc.). $20.2 \%$ used dietary supplements because they thought they did not get all the necessary nutrients from their diet. $18.3 \%$ had chronic diseases and were in need of medication. $47 \%$ were regular smokers.

\section{Comparative analysis}

The results of the comparative analysis of the dietary habits of the two groups are shown in Table 1. Table 2 shows the results of the comparison of demographic and anthropometric data.

\section{Analysis of the FFQ}

Though it seems there are many differences between the two groups the difference in the consumption of particular food products is statistically important ( $p$-value $<0.05$ ) in only 8 of them. Consumers of organic food eat more apples or pears, oranges, apricots, prunes, peas, whole wheat bread and less fried food. Table 3 shows the exact frequency of consumption between the two groups.

Table I Comparison of the dietary habits of people who consume organic and conventional food

\begin{tabular}{llll}
\hline Dietary habit & Consumers of organic food & Consumers of conventional food & p-value \\
\hline Eating breakfast & $70.6 \%$ & $71.8 \%$ & 0.88 \\
Having 3 or more meals a day & $57.1 \%$ & $55.1 \%$ & 0.82 \\
Eating home made food & $13.5 \%$ & $10 \%$ & 0.54 \\
Eating junk food I-2 times a month or less & $51.1 \%$ & $37.5 \%$ & 0.15 \\
Eating lean meta & $76.9 \%$ & $72.5 \%$ & 0.5 \\
Cooking mostly with olive oil & $98.1 \%$ & $100 \%$ & 0.21 \\
Consuming 2 alcoholic beverages a week or less & $80.8 \%$ & $77.5 \%$ & 0.65 \\
Not using dietary supplements & $78 \%$ & $80.8 \%$ & 0.7
\end{tabular}

Table 2 Comparison of anthropometric and demographic data

\begin{tabular}{llll}
\hline Anthropometric or demographic data & Consumers of organic food & Consumers of conventional food & p-value \\
\hline BMI $>=25$ & $54,9 \%$ & $47,4 \%$ & 0,01 \\
Married people & $72,9 \%$ & $50 \%$ & 0,61 \\
University and master's degree & $55,8 \%$ & $51,3 \%$ & $90,9 \%$ \\
Annual income $<=25000 €$ & $94,9 \%$ & & 0,53 \\
\hline
\end{tabular}


Table 3 Frequency of consumption of different food groups among people who eat organic and conventional food

\begin{tabular}{lll}
\hline Frequency of consumption & Consumers of conventional food \\
\hline Food product & Consumers of organic food & I serving a week up to I serving a day \\
\hline Apples or pears & $2-4$ servings a week up to I serving a day & I serving a week up to 5-6 servings a week \\
Oranges & $2-4$ servings a week up to I serving a day & I serving a week up to 5-6 servings a week \\
Apricots, prunes & I serving a week up to I serving a day & I-3 servings a month \\
Peas & I serving a week & I serving a week \\
Whole wheat bread & 2-4 servings a week & I-3 servings a month \\
Tea & I serving a week & I serving a week \\
\hline
\end{tabular}

\section{Discussion}

The analysis of the questionnaires showed that most of the participants were married women between 19-50years of age, with a high school diploma, an annual income of 10001-15000 $€$ and $50 \%$ of them had no children. They got the information they needed about nutrition mostly from the media, thus making this information less scientifically based. They had healthy dietary habits in general mostly due to the continuous attention that nutrition has been getting in the media, since people are more interested in staying healthy and beautiful for as long as they can.

Less than $40 \%$ of the samples are regular organic food consumers, which is mostly due to their high price, ${ }^{3}$ the lack of easily prepared meals for the children of working mothers, the smaller production of organic food and their appearance. ${ }^{4}$

The main reasons for purchasing organic food instead of conventional were:

a. They considered them safer since they are produced without the use of pesticides, fertilizers and antibiotics.

b. They thought they tasted better.

c. They considered them more nutritious, although there is no scientific evidence about that. ${ }^{5}$

Consumers of organic food products bought them mostly from super markets or from producers and not from organic food stores. That was maybe because it is easier to buy organic food along with all the household provisions and also because there are not many organic food stores in every neighborhood. What is really interesting is that people thought that fruit and vegetable they grow in their own gardens are organic, which shows that they were not aware of the strict European legislation about organic food production.

The products people preferred were fruit and vegetables, followed by olive oil, milk, dairy products, meat and pasta, though only $60 \%$ of them had proper European labeling. So, people bought conventional food thinking they were buying organic.

There were some common characteristics between the consumers of organic food. They were married women, with at least one child, who wanted to provide their families with safe food products, ${ }^{6}$ between the ages of 35-50, since younger or older people are not very concerned with health, food safety and environmental issues. ${ }^{4}$ They had a higher education level and an annual income up to $25000 €$. People with higher incomes avoid organic food due to their appearance. ${ }^{7}$
There were no differences in their general dietary habit, except that organic food consumers eat less frequently at restaurants or take out food since they don't have many choices of such places to eat. ${ }^{8}$ It has to be pointed out that the only common characteristic that was statistically important in this study was the marital status. The FFQ analysis showed that organic food consumers ate more skimmed or semi skimmed milk, cheese, margarine, apples, pears, oranges, apricots, prunes, broccoli, peas, tomatoes, breakfast cereals, whole wheat bread and drunk more wine. Also, they ate less butter, minced meat, cured meat products, chocolate, white bread, chips, rice, pasta, French fries and fried food in general. Therefore their diet was richer in vitamins, antioxidants, vitamin $\mathrm{C}$, calcium and fibers and poorer in saturated fat, cholesterol, salt, simple carbohydrates and energy. Again, the only differences those were statistically important were oranges, apples, pears, apricots, prunes, peas, whole wheat bread, French fries and fried food in general.

\section{Conclusion}

This study reveals a pattern among people who consume organic food and a tendency to healthier dietary habits, but needs a further exploration in order to obtain more statistically important data.

\section{Acknowledgements}

This article is a review of my master paper in Public Health and Food Safety, in the department of Medicine in the University of Thessalia. (My supervisors were Dr. Chatzichristodoulou Christos, Dr. Karidis Ioannis and Dr. Rachiotis Georgios).

\section{Conflict of interest}

The author declares no conflict of interest.

\section{References}

1. Willet Walter. Nutritional Epidemiology. USA: Oxford University Press; 1990. p. 52-126.

2. Colditz GA. The Nurse's Health Study: A cohort of US women followed since 1976. J Am Med Womens Assoc. 1995;50(2):40-44.

3. Cicia G, Teresa DG, Riccardo S. Consumer's perception of quality in organic food. A random utility model under preference heterogeneity and choice correlation from rank ordering. British Food Journal. 2002;104(3/4/5):200-213.

4. Padel S, Carolyn Foster. Exploring the gap between attitudes and behavior. British Food Journal. 2005;107(8):200-213. 
5. Magos F, Arvaniti F, Zampelas A. Organic food: Nutritious food or food for thought? A review of the evidence. Int J Food Sci Nutr. 2003;54(5):357-371.

6. Gaetano Chinnici, Mario D’Amico, Biagio Pecorino. A multivariate analysis on the consumers of organic products. British Food Journal. 2002;104(3/4/5):187-199.
7. Francisco Soler, José M Gil, Mercedes Sánchez. Consumer's acceptability of organic food in Spain: Results from an experimental auction market. British Food Journal. 2002;104(8):670-687.

8. Thompson GD. Consumer's demand in organic food: what we know and what we need to know. American Journal of Agricultural Economics. 1998;80(5):1113-1118. 